\title{
Transformation in Weaving Technology of Paata-Clothes: an unique Fabric Tie-Dye product of Odisha
}

\author{
Rudranarayan Mohapatra, Sadananda Dutta
}

\begin{abstract}
Both in global market and in perspectives of modernization, preserving and popularizing the traditional weaving technique and designing, is a challenge of 21st century. As it seems, the handloom weaving is unsustainable, and unable to compete in contemporary markets, but it realized, many weavers struggle for livelihoods irrespective of old fashion outcome and to preserve their ethnic and traditional proficiency identity. Odisha, the east-coast state of India is one of them, where thousands of ethnic weavers' are adopting their parental knowledge of weaving and preparation of micro Ikat garments in tie-\&-dye technique generation after generation. In this paper, we are trying to establish the gradual transformation in weaving technology replacing but preserving traditional weaving technique. And to establish we catalyzed here the preparation of 'Paata-clothes', one of the rarest tussar-silk fabric, produced by 'Nuapatana' master weavers. The paper followed the field based research method that is being practically followed by Nuapatana weavers and gets the resultant of productivity changes by relative analysis techniques.
\end{abstract}

Keywords: Paata, Taani (warp), Varani (weft), Ikat (bandha), Tie-\&-Dye, Odisha, Khandua-Paata, maanku (Shuttle)

\section{INTRODUCTION:}

The role of handlooms in ultimate industry and art traditions of Odisha is unique. For hundreds of years, many hand-woven garments made from yarn and silk have gained popularity from Odisha at the country and abroad. Handloom weaving in Odisha's Sambalpur, Sonpur, Boudh, Tigiria and other places has its own style and uniqueness. Of these, the art, craftsmanship and beauty of the cloth woven by the weavers of Tigria are the most peculiar. Historically, no information has been found on the origin of the handicrafts of these hand-weavers in Odisha. However, it has been used by many weavers for hundreds of years. Recent advances in science and technology have led to many changes in their hand-woven technology. The application of the machine has increased in terms of technical know-how, and a traditional weaver has gradually changed its technique. In this context, there is a need to re-evaluate the techniques used by weavers in Odisha

Revised Manuscript Received on May 09, 2020.

* Correspondence Author

Rudranarayan Mohapatra*, P.G. Department of Odia, Utkal University, Bhubaneswar, India. Email: rudrautkal@gmail.com

Sadananda Dutta, Odia department, Govt. Autonomous College, Phulbani, Odisha, India. Email: sadananda.uu@gmail.com

(C) The Authors. Published by Blue Eyes Intelligence Engineering and Sciences Publication (BEIESP). This is an open access article under the CC BY-NC-ND license (http://creativecommons.org/licenses/by-nc-nd/4.0/) in the $21^{\text {st }}$ century. In this research article, we are trying to evaluate and present the artwork of the very famous 'Paata-clothes (a very rare Silk fabric produced by Nuapatna master weavers)' from various textiles woven at Nuapatna village in Tigria district of Odisha.

\section{AIM OF THE STUDY:}

The purpose of the stud of research paper is -

- Briefing the traditional technique of preparing Paata-Sari

- Inclusion of modern equipments and the changes occurred in its production and artistic excellence.

- Demand of Paata-clothes in market for this specialty and development of economic life of weavers

\section{LITERATURE REVIEW:}

While Odisha's traditional handlooms have created a special place for perfect craftsmanship, excellent fabrication and attractive design, Odisha's tie-\&-dye clothes or Ikat garments have gained special popularity among consumers. Therefore, Paata cloth has a pioneered culture and tradition for its Ikat weaves created by an intricate process called the "bandha" in which warp and weft threads are tie-dyed to produce the pattern on the loom while weaving (S. Behera \& et.al, 2019). The traditional Khandua-Paata cloth has been made by weavers for last 800 years in and around at Nuapatna of Cuttack district of Odisha, India. Not only in Odisha, but also at abroad, Khandua-Paata has lot popularity. Khandua-Paata clothes are closely associated with the Lord Jagannath culture. The Khandua Paata has long been used as the wearing clothes of Lord Shree Gannath, Balabhadra and Subhadra at Jagannath temple of Odisha, the epitome of Odia culture (Tripathy A.K, 2003). However some skilled weavers make this Paat exclusively. It is believed that in the $12^{\text {th }}$ century, the poet Jayadeva inscribed the Gita Govinda verse on a cloth with tie-\&-dye technique and offered it to Lord Jagannath. And it had been used as the wearing clothes of lord Jagannath (A. Buhler, 1980). However, in traditional Paata-clothes, different animals like Elephants, lions, plants, flowers and vines were being painted, and the same still continues. The Anchal (pallu) is adorned the most with motifs and designs, is seen as the auspicious end of the garment that serves as a reminder of both god and tradition. Attractive Khandua Paata clothes and yarns are made up of using red, black, yellow, green and tied yarns. The ikat clothes were exhibited at the Victoria-Albert Museum in London in the 1850s. Odisha's tie-\&-dye handloom sari was also on display in Paris, including the

Published By:

Blue Eyes Intelligence Engineering

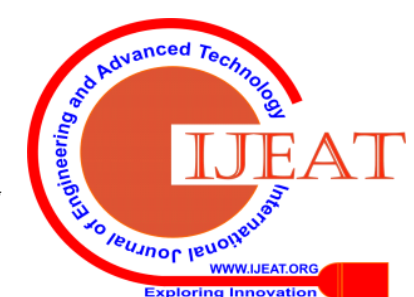


museum. And presently it is a geographically tagged product of Odisha since 2007.

\section{IV.}

EXCLUSIVENESS OF NUAPATNA PAATA:

Paata sari, as the exclusive (a rare silk fabric) product derived from bandha kala (resist dyeing and weaving technique), has a unique identity in Odisha since 600 B.C. Demand for this unique Paata Sari in context to weaving technology has grown significantly and today also not reduced (O.H. Buletin 2009). The state had 43,652 handloom units in 2009 , and it rises up to 55,790 in 2019 . According to the 2017-18 Census, Cuttack has 18,330 handloom weavers and other associated workers. In modern times, people are even not aware the importance of a Paata sari. This Paata sari is a unique handicraft item made exclusively manually. Paata saris were not woven here by machine, but here to say that, only the help of modern technology its production increases significantly in last some years. The village of Nuapatna, especially in the Tigiria block of Cuttack district, has maintained its reputation at the regional, national and international levels for its 'Khandua Paata-sari'. The Paata Sari of Nuapatna has a variety of body-tied design. The variety of saris included in that body-ikat design are--

- Khandua Paata

- Tarabali Paata

- Plane Kumbha Sari

- Pasha Pali Design Sari

- Jala Design Sari

- Bomkei Design Sari

- Paata Joda

In addition, there are many other Paata cloth designs are also prepared in this region. Weavers weave the verse of the famous Sanskrit poet Jayadeva's Gitagovinda in beautifully refined letters which are regularly offered to Lord Jagannath. The following is a sample of verse weaved in Paata cloth (Fig. No 1):

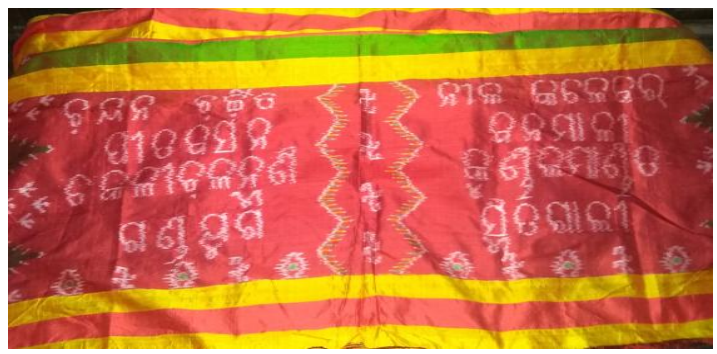

Fig. No .1: A piece of Paata cloth where the verse of Gitagovinda is weaved

\section{V. \\ TOOLS AND SUB-TOOLS WITH TIE-\&-DYE HANDLOOM}

- Maanku (Shuttle) - it is looks like a boat through which the weft yarn wound sets into a shuttle and the shuttle passes back and forth through the warp shed, and releases weft yarn from the Pirn (bobbin).

- Kanda (Pirn Bobbin) - A Pirn is a small rod onto which weft thread is wound for use in weaving. It is fixed in a place of shuttle.

- Pania (reed) - It resembles as a comb. It is used to separate and space the warp threads, to guide the shuttle's motion across the loom, and to push the weft threads into place.
- Dakti (heddle) - A cord or wire has an eye in the center where the warp is threaded through and it is suspended on reed.

- Baw-kathi (heddles stick) - The two pieces sticks on which reeds heddle thread are tied.

- Nachuni (beater) - Beater from where the heddles are suspended just like a balance. It is designed to push the weft yarn securely into place.

- Chitikini - The piece of wood which strikes on the right or left side holding in hand, the beater moves through a rope.

- Bharani Suta (Weft) - The crosswise threads on a loom that are passed over and under the warp threads to make cloth.

- Naraja (Warp Roller) - The thick round bar on which the warp is wrapped

- Taasana (Brush) - Brush used to clean the yarn

- Tipini-danda (Treadles) - Is a mechanism located at the bottom of the loom and are designed to control warp shed formation by controlling the up and down movement of the heddles.

- Tipini-daudi (Treadles-rope) - the rope connecting to treadles and heddles

- Mati - Two sticks designed Just like ' $\mathrm{X}$ ' that keeps tightening the end point of the cloth.

- Mendhi (Beater) - A piece of wood attached to a rope that moves the shuttle.

- TuliKaatha (Cloth Roller) -The roller bar on which the woven part of cloth is rolled

- Lis or Lis-kathi - Thread of the warp

- Drum - A hollow drum like frame on which the warp and weft wound around

- Chadiki - A traditional winding device that divides hank yarn to warp and weft (Fig No. 2)

- Nataa- A traditional device on which the warp wound around (Fig No. 3).

- Other special equipments are Vishwakarma, Jaw-Kathi, Naraj, and Daankiaa etc.

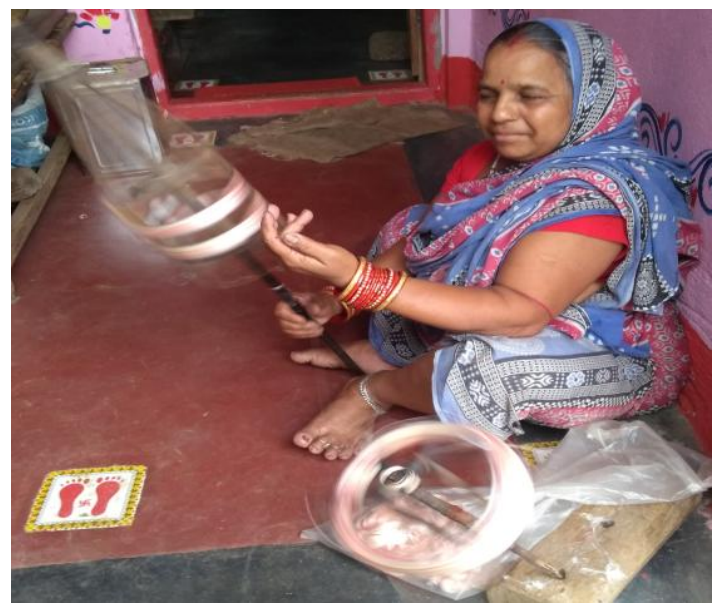

Fig. No .2 - 'Nataa' and 'Chadiki' used for divide yarn to warp and its winding

Published By:

Blue Eyes Intelligence Engineering

Retrieval Number: E9480069520/2020@BEIESP

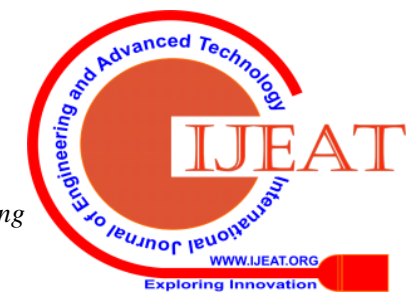


VI.

\section{WEAVING TECHNIQUE AND ITS DIVISION:}

The word 'tie' means bind. This weaving technique referred as tie-and-dye technique in various parts of the Asian continent. In the art of tie-\&-dye weaving, the necessary designs are made by knitting the yarn long before the weaving. However, in other textile engineering, the designed are done after weaving or on the loom itself at the time of weaving. The art of weaving is very different from print or weaving techniques. In this technique, the weavers are allowed to precisely prepare the patterns that appear on the finished fabric. Then the pattern is first sketched on paper and transferred onto the yarn. Therefore the Paata are immersed in color as proper coordinating with Paata-knots and its open areas. The die- $\&$-dye technique, is the unique artistic technique, specially developed by the wavers of Odisha long before. Various government incentives have been provided through cooperatives to develop the technique since independence. However, so far no concrete efforts have been made to create this unique and micro technical market. Presently, the traditional designs of tie- $\&$-dye clothes are gradually disappearing. Therefore the proper preservation and modernization of this technique demands to revive itself in world market. The preparation and process of 'Ikat' at Nuapatana is accomplished through a number of special steps.

- Warping (Preparation of vertical yarn or warp ikat, localized as 'Tani') Technique

- Coloring or dyeing Technique

- Wefting (Preparation of horizontal yarn or weft Ikat, localized as ' Varani'

- Weaving

\section{(a) Warping:}

At the outset, the overall equipment can be monitored to make the entire fabric. By this process, as a chunk, the warp, the local term 'Taani' is prepared for 32 pieces of cloth. For this $4 \mathrm{~kg}$ Taani-Paata (the raw warp) is required. Therefore preparing a single sari the weavers need average of 125 gm raw warp yarn. The Taani-Paata puts together as "2 Ply Taani 1820 Stressing Bala" as per the model / brand.

- In next, $4 \mathrm{~kg}$ of Taani-Paata is heated in a hot oven with soapy water and caustic soda as needed and cleaned for 45 to 55 minutes. For $4 \mathrm{~kg}$ Taani, 100gm Caustic Soda and 4 soaps weight of $50 \mathrm{gm}$ each are required. It is then washed thoroughly in plain water and dried in heat.

- If the warp requires to be colored, then the color is mixed as of need. Thereafter in another bowl, the Taani (warp) again thoroughly washed with clean water and dry under the sun.

- After drying in the heat, the yarns are rolled in Nataa with the help of Chadiki.

- Once rotated, the Taani is allowed to be rolled to "drum". (Flowchart No. 1)

- When wrapped in drums, the silk and mercerized flower-Taani are put further for the border of the cloth and then it marked on every 12 yards (18 ft.).

- Then, the Taani is wrapped with the help of Naraaz (Warp-roller) to make the cloth. Once the Taani is ready, its every thread is knitted with the help of heddle and riddle. And then rolled further to another Naraaz (Warp-roller).

- There after what type of design flowers required for the fabric border, are made of silk with the help of a dobby.
- Then the booties (small flowers on the body of the cloth) are tied.

\section{(C) Coloring or dyeing Technique:}

Dyeing is one of the most important value addition processes of handloom garments. The dyeing process is either carried out by the yarn trader before selling the yarn or by the master weavers. Here in Nuapatana, the weavers do their dying process as per designing. In past, weavers used to make natural dyes by mixing various natural materials, such as tree bark, leaves, stones, charcoal, green and gogul. However, various chemical dyes are currently being used. Common among them are the Trinitro-phenol, Methanol Yellow, Cloth Red 2B and Fine Blue etc. However, depending on the size of the stretcher or strap, the Color combination (Puta) of the color varied these chemical colors have extremely limited use. For instance the color preparation formula among Nuapatana weavers presently as follows:

\begin{tabular}{|l|l|l|l|}
\hline S.N & $\begin{array}{l}\text { Preparing } \\
\text { Color }\end{array}$ & $\begin{array}{l}\text { Color } \\
\text { Combination }\end{array}$ & Ingredients \\
\hline 1 & $\begin{array}{l}\text { Algae color } \\
(1 \mathrm{~kg})\end{array}$ & Two Colors & $\begin{array}{l}\text { Blue: } \\
\text { 2gm/3gm } \\
\text { Acid: } 30 \mathrm{gm} \\
\text { BT: } 20 \mathrm{gm}\end{array}$ \\
\hline 2 & $\begin{array}{l}\text { Orange color } \\
(1 \mathrm{~kg})\end{array}$ & $\begin{array}{l}50 \text { gm } \\
\text { Orange } \\
\text { Color }\end{array}$ & $\begin{array}{l}\text { Acid: } 30 \mathrm{gm} \\
\text { Pink: } 5 \mathrm{gm}\end{array}$ \\
\hline
\end{tabular}

The Nuapatana Weavers dyeing process follows a combination of basic Chemicals such as Caustic Soda and Acid such as Sulphuric acid or Acetic acid etc. Therefore, here a point to say that, the process of this form of dyeing is, however, time consuming and expensive. As practice, the Nuapatana weavers, taking the half-dried yarn dipped in hot water again. And after this, when the threads are finally dyed, colors are absorbed easily and evenly.

\section{(b) Weft Technique:}

At the outset, Malda-Paata (the localization of hank yarn for 'weft' as it generally purchased by them from Malda city, Bengal) soaked in plain water for 7 to 8 hours. Once completely soaked, the water is heated by placing a large pot in a hot oven. Then the Weft (Varani Suta) cleaned for 45 to 50 minutes adding caustic soda and soap as needed. After cleaning, it is thoroughly washed with plain water and dried in the sun. After drying, it is rolled into Naata with the help of a chopstick (Chadiki). After turning around in the Nataa, it is again dug into the flour paste and pounded into water for its softened. It is then rolled back (same in wet condition) into a Nataa. It is point to say that the flour is given to warp for its smoothness. After rolling in the Nataa, it dries out in the heat with the Nataa. Once it is dry, it is rolled back with other Nataa. When spinning in this Nataa, a thick 'khiya' is made by mixing one thread with two or three thread. The five thick threads are then rolled through a Chadiki with the help of one Nataa to make eight Nataa. These eight Naatas are given for row preparation. However, the Dhadi (boarder of the Sari) treats in different process and it rigorously follow the resist dying technique in weft.

\section{Published By:}

Blue Eyes Intelligence Engineering
\& Sciences Publication

(C) Copyright: All rights reserved.

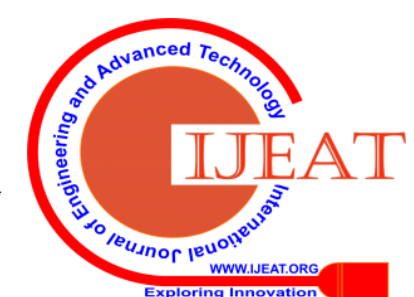


The boarders are prepared and resist marked and tied as per design (as desired). The color of the border is made after the resist tying process. This tying process is done tightly with polythene and yarn (Fig. No.2).

The body of boarder is then dyed and washed thoroughly and dried in the sun. As the boarder dry-out the polythene and yarns tied in boarder are removed.

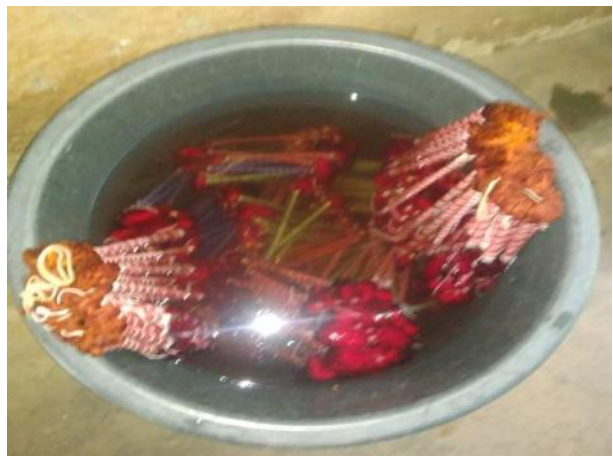

Fig. No. 2: Resist color tying of boarder

There after the Wefts are then divided into eight Nataas as before. However, the activity is performed by eight members and in many cases members of the weaver family helps to complete the task. Then, as before, the thick thread from the Nataa is tied to one thread. It is again extracted from Nataa and put back in Chadiki. It is then wrapped in a pirn with the help of 'AraTa (Wheeler)'.

\section{(d) Weaving technique:}

The weaving process of Paata clothes follows two types of weaving technique. These are, (a) Single Ikat, (b) Double Ikat. In single Ikat weaving process warp or weft yarn either of them kept in solid color, where the other one goes through the process of resist dyed. However, in double Ikat technique, both warp and weft are gone through the resist-dyed repeatedly. When they are woven in place, the final pattern gradually developed as designed. So this type of weaving desires more experience and mastering proficiency. Before weaving starts -

The pirn (Nali) is inserted into the Maanku (Shuttle) and the cloth is woven through the legs and arms. At this point, the Maanku is periodically removed from the stalk (Hataa) and oiled, making it easier to weave. (Fig. No. 3)

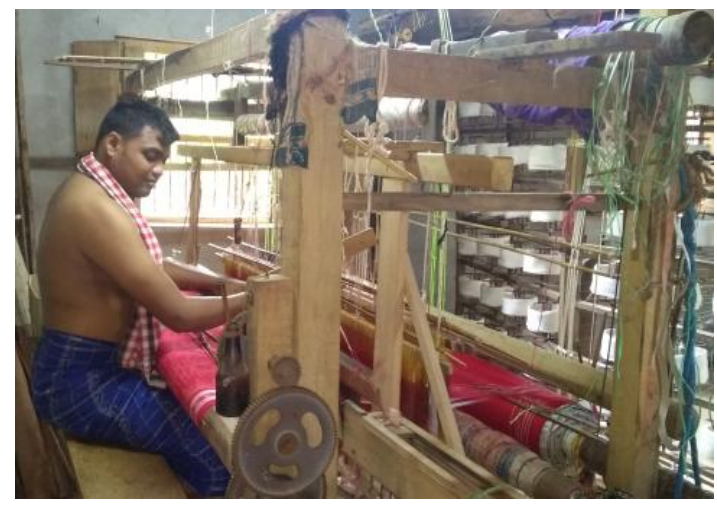

Fig No 4: Weaving of Clothes

In this way, the body and Anchal of sari are woven till the 12 yards (216 inch) and rolled on Naraz, the Warp-Roller. From weft preparation to Weaving process repro-steps are as follows in FlowChart-2. After the cloth is cut at a distance of
12 hands, it is given for 'Pocho' (Paste made from flour). It is then dried again in the sun. When it dries, it is folded and sold.

\section{DRAWBACKS AND THE IMPACT OF NEW TECHNOLOGY:}

In the above traditional approach, the application of new know-how has been adopted by focusing on the following three aspects;

- Low production

- The use of time-consuming clothing systems such as small Taani and manual equipments.

- Lack of raw materials for traditional color preparation

- Low quality and incorrect colors available in the market

- Weavers have lack of modern machinery knowledge

In view of the above shortcomings, some modern equipment has now been used to change the way weaving is done. These devices are -

- Cabinet diving machine

- Hydro Extractor

- Bobbin and washing machine

\section{OUTCOMES:}

By using above modern equipments, here is the comparative analysis in production of two Paat sari of market price Rs.10, 000/- is shown below.

\begin{tabular}{|l|l|l|}
\hline $\begin{array}{l}\text { Manual } \\
\text { process }\end{array}$ & $\begin{array}{l}\text { Consume time } \\
\text { in the old } \\
\text { system }\end{array}$ & $\begin{array}{l}\text { Consume time in New } \\
\text { technique }\end{array}$ \\
\hline Warping & $4 \mathrm{hrs}$ & 50 Minutes \\
\hline Pirn Winding & $4 \mathrm{hrs}$ & 35 Minutes \\
\hline $\begin{array}{l}\text { Rolling Wefts } \\
\text { in Chadiki }\end{array}$ & $3 \mathrm{hrs}$ & 20 Minutes \\
\hline $\begin{array}{l}\text { Rolling the } \\
\text { Wefts }\end{array}$ & $2.5 \mathrm{hrs}$ & 20 Minutes \\
\hline $\begin{array}{l}\text { Rounding lkat } \\
\text { (bandha) }\end{array}$ & $1 \mathrm{hrs}$ & 10 Minutes \\
\hline Total & $14.5 \mathrm{hrs}$ & $2 \mathrm{hrs} \& 15$ Minutes \\
\hline
\end{tabular}

Table No 1: Technique \& Time Compare

The above modern garment techniques have helped save both time and labor compared to the previous one. As a result of-

- the increase in production increased about 7 times;

- the weaving capacity of weavers has increased;

- Cleanliness and well-being in the environment have improved;

- The socio-cultural ethnic style blended with socio-technical design.

\section{CONCLUSION:}

Nuapatna weavers have been able to keep intact the ancient and modern designs in tie- $\&$-dye garments. Its all credit goes to skilled weavers. People's mindsets have changed over time, therefore the handloom weavers. They used to be traditional, but now they have changed the way they weave.

Blue Eyes Intelligence Engineering ciences Publication (C) Copyright: All rights reserved. 
Leaving the conservative and traditional methods, the tie-dyed weaving has gone a long way today. Jala, Dubi and Zakard, and the other areas, the revolutionary change has been brought. By changing the technique, the day's work has been done in just a few hours.

\section{REFERENCE:}

1. 'Odisha handloom Buletin', $1^{\text {st }}$ year December $2009,1^{\text {st }}$ part, Editor: Laxmi Narayan Nayak, State Handloom Directorate, Govt. of Odisha

2. Tripathy Ajit Kumar, 'Shri Jayadev O Khandua paat', SriMandir-2003

3. Kedar Mishra, 'Sukhma Sutara Varnila Kabita; Baandha Kala O Sambalpuri Hastatantara Gaatha', Samikhya Bureau, February 25, 2019

4. Annapurna Mamidipudi \& Wiebe E. Bijker, 'Innovation in Indian Handloom Weaving', Technology and Culture, Volume 59, Number 3, July 2018, pp. 509-545, Published by Johns Hopkins University Press;

5. https://doi.org/10.1353/tech.2018.0058

6. Sahu Ipsita, 'The Sambalpuri Textile Weaving Process' Sahapedia, Published 06 Nov 2017, Accessed on 09.05.2020; https://www.sahapedia.org/the-sambalburi-textile-weaving-process

7. 'Exploring the Techniques of Ikat', STRAND OF SILK, Accessed on 07.05.2020

8. 'Sudarsan Behera \& et.al.', 'An insight into the ikat technology in India: ancient to modern era' IOSR Journal of Polymer and Textile Engineering (IOSR-JPTE) e-ISSN: 2348-019X, p-ISSN: 2348-0181, Volume 6, Issue 1 (Jan. - Feb. 2019), PP 28-51, www.iosrjournals.org

9. A. Buhler, E. Fischer and M. L. Nobholz.,,,Indian Tie - Dyed Fabrics (Vol.4, P.3-4, 1980).

10. 'Annapurna Mamidipudi \& et.al.', 'Innovation in Indian Handloom Weaving', Technology and Culture, July 2018

11. https://www.researchgate.net/publication/327840884

\section{AUTHORS PROFILE}

Dr. Rudranarayan Mohapatra: Assistant Professor, P.G. Department of Odia, Utkal University, Vanivihar, Bhubaneswar, Odisha

Mr. Sadananda Dutta: Assistant Professor (OES), Govt. Autonomous College, Phulbani, Odisha and has an expertise in weaving. 
Transformation in Weaving Technology of Paata-Clothes: an unique Fabric Tie-Dye product of Odisha

APPENDIX: I

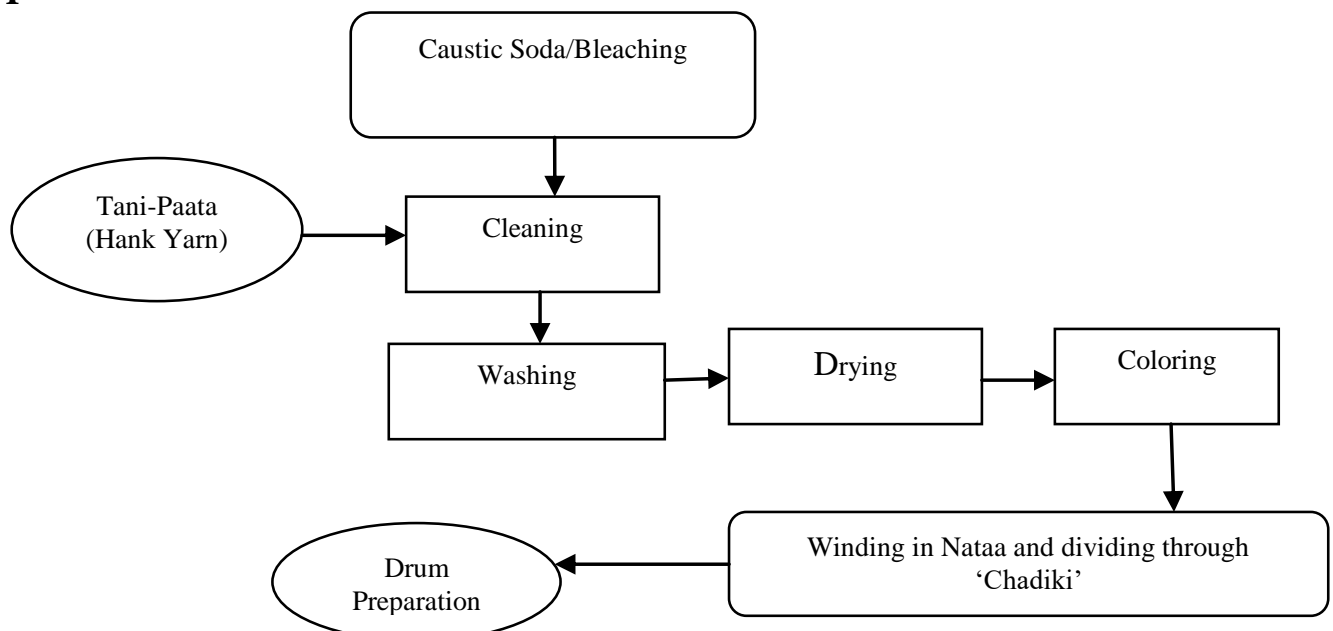

Flow-Chart No. 1: Drum is prepared from Taani Paat

APPENDIX: II

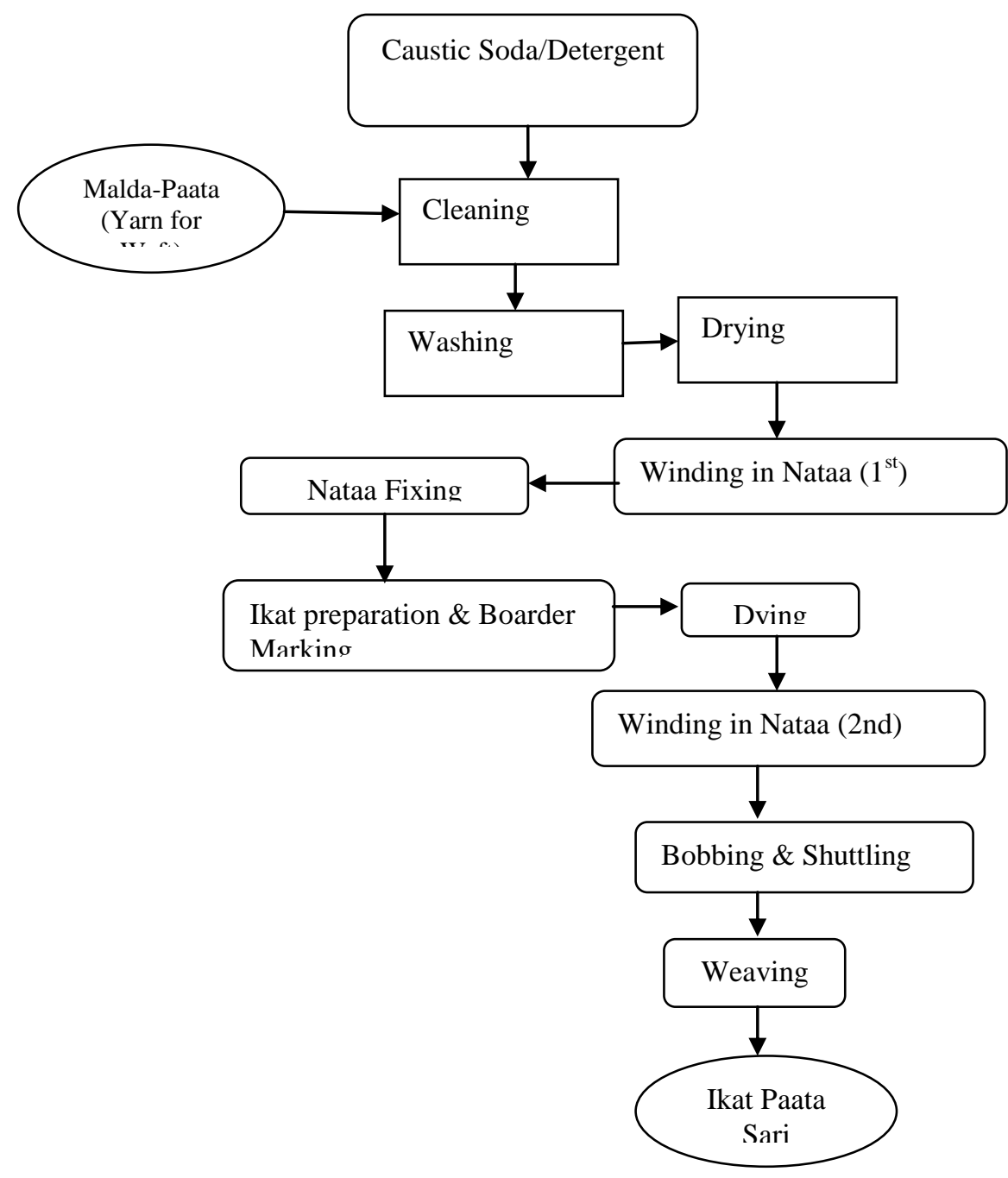

Flowchart No.-2: Repro-steps of Weft and Weaving 